\title{
LIVER CANCER MORTALITY AND FOOD CONSUMPTION IN SERBIA, 1991-2010: AN ECOLOGICAL STUDY
}

\author{
Milena Ilić1, Kristina Radoman², Slavica Konević ${ }^{3}$, Irena llić ${ }^{4}$ \\ 'Department of Epidemiology, Faculty of Medical Sciences, University of Kragujevac, Kragujevac, Serbia \\ ${ }^{2}$ Medical High School in Podgorica, Podgorica, Montenegro \\ ${ }^{3}$ Department of Specialist Consultancy Services, Health Centre Rakovica, Belgrade, Serbia \\ ${ }^{4}$ Faculty of Medical Sciences, University of Kragujevac, Kragujevac, Serbia
}

\begin{abstract}
SUMMARY
Aim: This paper investigates the correlation between liver cancer mortality and consumption of food-groups in Serbia.

Methods: We conducted an ecological study. The study comprised the population of the Republic of Serbia (about 7.5 million inhabitants) during the period 1991-2010. This ecological study included the data on food consumption per capita which were obtained by the Household Budget Survey and mortality data for liver cancer made available by the National Statistical Office. Linear trend model was used to assess a trend of age-adjusted liver cancer mortality rates (per 100,000 persons) that were calculated by the method of direct standardization using the World Standard Population. Pearson correlation was performed to examine the association between liver cancer mortality and per capita food consumption quantified with a correlation coefficient ( $r$ value).

Results: In Serbia, over the past two decades a significantly decreasing trend of liver cancer mortality rates has been observed $(p<0.001)$. Liver cancer mortality was significantly $(p<0.01)$ positively correlated with animal fat, beef, wine and spirits intake $(r=0.713,0.631,0.632$ and 0.745 , respectively). A weakly positive correlation between milk consumption and mortality from liver cancer $(r=0.559, p<0.05)$ was found only among women. The strongest correlation was found between spirits consumption and liver cancer mortality rates in women $(r=0.851, p<0.01)$. Anegative correlation between coffee consumption and age-adjusted liver cancer mortality rates was found $(r=-0.516, p<0.05)$ only for the eldest men (aged 65 years or older).

Conclusions: Correlations between liver cancer and dietary habits were observed and further effort is needed in order to investigate a possible causative association, using epidemiological analytical studies.
\end{abstract}

Key words: food consumption, alcohol, correlation, liver cancer, mortality trend

Address for correspondence: M. llić, Faculty of Medical Sciences, Department of Epidemiology, University of Kragujevac, S. Markovica 69, Kragujevac 34000, Serbia. E-mail: drmilenailic@yahoo.com

http://dx.doi.org/10.21101/cejph.a4168

\section{INTRODUCTION}

Liver cancer is the third most common cause of cancer mortality worldwide, with estimated 696,000 deaths accounting for $9.2 \%$ of all cancer deaths during 2008 (1-3). Liver cancer is one of the deadliest malignant tumors, with survival rate lesser than $11 \%$ even in the developed countries (4). In 2008, more than half of the liver cancer-related cases were registered in China (2). Hepatocellular carcinoma is the main histological type, accounting for over $80 \%$ of all liver malignancies (5).

Liver cancer mortality is on the rise in regions with low rates including the European Union countries (6) and the United States of America (7), and is on the decline in high-risk regions including urban areas of China and Japan $(8,9)$. International differences in liver cancer mortality might be explained by genetic and environmental factors, but studies of migrants show that exposure to environmental factors plays a dominant role (10). An increased incidence of hepatitis $\mathrm{B}$ and $\mathrm{C}$ infections is considered the main cause for rise in liver cancer mortality $(11,12)$. Hepatitis $\mathrm{C}$ and $\mathrm{B}$ viruses are the major risk factors for hepatocellular carcinoma (11). Globally, it is estimated that approximately three-quarters (78\%) of liver cancers were attributable to HBV $(53 \%)$ or HCV (25\%) (11). The global prevalence of chronic HBV and HCV infection largely explains the prevalence of liver cancer. In most developed countries, drug injection and high risk sexual behaviour are the main risk factors for HCV and HBV infections.

Alcohol use was one of the leading risk factors for death from cancer, accounting for $25 \%$ of liver cancer deaths worldwide (in low- and middle-income countries for $23 \%$, in high-income countries for 32\%) (13). However, in the United States of America it is estimated that $15-50 \%$ of liver cancer cases do not have evidence for the risk factors of either viral hepatitis or heavy alcohol consumption (14).

The role of diet in the aetiology of hepatocellular carcinoma is unclear, except for aflatoxin contamination. Aflatoxin exposure is a significant factor in the high incidence of liver cancer, especially 
in regions where food contamination with Aspergillus fumigatus fungi is common (15). Findings from recent meta-analyses suggested that an increased consumption of coffee may reduce the risk of liver cancer (16). Coffee has also been shown as a protective factor in individuals infected with HBV or HCV (17). In several studies, inverse associations were observed for vegetable and fruit intake, and fish and eggs consumption, while meat intake was directly associated with risk of liver cancer (18-20). Some other studies did not confirm these findings (21-23).

There were not many ecological studies that assessed link between the consumption of food and liver cancer, either in one country or at the international level. The aim of this study is to analyze time trend in liver cancer mortality in Serbia in correlation to changes in per capita food and alcohol consumption.

\section{MATERIALS AND METHODS}

The study comprised the population of the Republic of Serbia (about 7.5 million inhabitants) and was based on data obtained from a nationally-representative survey conducted by the Statistical Office of the Republic of Serbia. It was an epidemiological study with an ecological design using data on mortality due to liver cancer in Serbia between 1991 and 2010. This study is a part of larger research approved by the Ethics Committee of the Faculty of Medical Sciences, University of Kragujevac, entitled "The survival of patients suffering from the most common chronic diseases (malignant tumors, cardiovascular and cerebrovascular diseases)".

\section{Mortality Data}

Mortality and demographic statistic data were collected and made available by the Statistical Office of the Republic of Serbia. Data for the Republic of Serbia, without the Autonomous Province of Kosovo and Metohija, for which data are unavailable since 1998, were presented in this paper.

For the analysis of death due to liver cancer (code 155 revision 9 in the period 1991-1996, and code C22 revision 10 from the year 1997 of the International Classification of Diseases to classify death, injury and cause of death) in Serbia, the unpublished data were obtained from the State Statistical Office. The Serbian population data were provided on the basis of official censuses from 1991 and 2002, while for inter-census years the estimates of the resident population were obtained from the State Statistical Office database.

The Death Cause Statistics in Serbia is fully compliant with international standards and recommendations (the UN Principles and Recommendations for a Vital Statistics System Revision 2, International Classification of Diseases, Eurostat) (24). The death certifiers are an authorized physician in healthcare organization, coroner or forensic physician. Death files are checked by the local registrar and forwarded to the referral public health institute where they are checked again and if necessary corrected by another trained medical doctor or specialist.

Three types of death rates were calculated: age- and genderspecific and age-standardized. Age-standardized mortality rates were calculated using the World Standard Population by the method of direct standardization. Also, truncated (40-64 years, and $65+$ years) mortality rates were computed for overall deceased from liver cancer (these data were shown only) and for both genders separately. Rates are expressed as deaths per 100,000 persons.

\section{Data on Consumption Per Capita}

The data on food and alcohol consumption per capita were obtained by the Household Budget Survey. The Household Budget Survey has been conducted on the entire territory of the Republic of Serbia. The data were collected for entire observed year, and every household was screened for the period of two weeks. The Survey utilized a diary method and questionnaire-based oral examination method (interview method) of the selected households. The Survey used a two-stage, stratified, rotating sample, with enumeration areas as the primary and households as the secondary units of selection. From the total number of households selected for the Survey, there was a continuous achievement of satisfactory percentage of surveyed households (over $85 \%$ ) during the survey period. Data quality assessment by phone was performed on a random sample (10\% of surveyed households) in each even quarter during the year. For a few years, data were missing for one or more food items. No extrapolation was made for missing data. Eight different food or food-groups were selected for comparison.

\section{Statistical Analysis}

The linear trend model was used to examine mortality trend from liver cancer. The Pearson correlation was performed to examine associations between liver cancer mortality and food consumption (quantified with a correlation coefficient, $r$ value). Correlation analysis was done for the age-standardized mortality rates at all ages and truncated rates (40-64 years, and 65+ years). Correlation analysis by gender was also performed. Two-sided $p$ values were reported and considered to indicate statistical significance when less than 0.05 . All statistical analyses were conducted using the Statistical Package for Social Sciences software (SPSS Inc., version 19.0, Chicago, IL).

\section{RESULTS}

\section{Time Trends in Liver Cancer Mortality in Serbia}

Mortality trends for liver cancer have declined significantly in Serbia, with rates decreasing by nearly 30\% since 1991 (6.2 per 100,000$)$ to $2010(4.2$ per 100,000) (Fig. 1).

Among females, liver cancer mortality rates were approximately two times lower than that in males (Fig. 2). Both males and females showed favourable trends, with a decline over the last two decades $(\mathrm{p}<0.001)$.

\section{Correlation between Liver Cancer Mortality and Per Capita Food Consumption}

Pearson correlations between age-adjusted liver cancer mortality rates and per capita food consumption are presented in Table 1. In Serbia, a significantly $(\mathrm{p}<0.01)$ positive correlation between liver cancer mortality rates and animal fat, beef, wine and spirits intake was demonstrated $(r=0.713,0.631,0.632$ and 


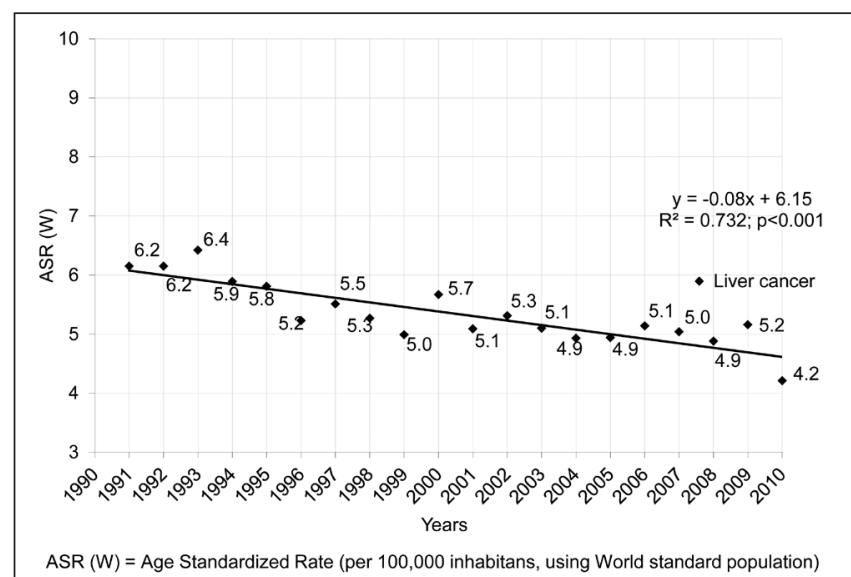

Fig. 1. Trend of liver cancer mortality in Serbia, excluding the Autonomous Province of Kosovo and Metohija, 1991-2010.

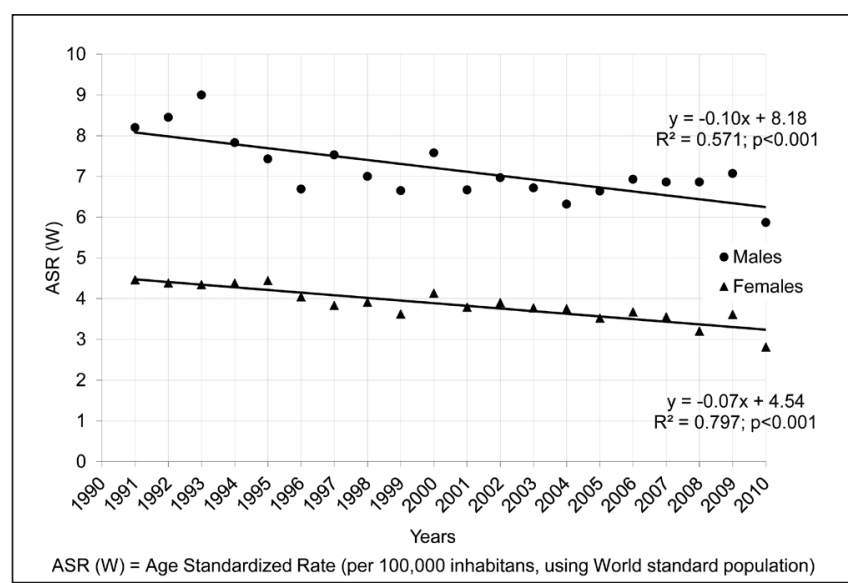

Fig. 2. Trend of liver cancer mortality in Serbia, excluding the Autonomous Province of Kosovo and Metohija, by gender, 1991-2010.

0.745 , respectively). Negative correlations were found between consumption of vegetable oil $(\mathrm{r}=-0.583)$, poultry $(\mathrm{r}=-0.728)$, dried meat and meat processed items $(\mathrm{r}=-0.666)$, fish $(\mathrm{r}=-0.678)$, eggs $(r=-0.789)$, yogurt $(r=-0.710)$, and beer consumption $(\mathrm{r}=-0.525)$ and liver cancer mortality rates. Except for apples, fruit and vegetable intake was significantly negatively correlated with mortality from liver cancer: citrus fruits $(\mathrm{r}=-0.690)$, potato $(r=-0.718)$, cabbage $(r=-0.703)$, pepper $(r=-0.572)$, and tomato $(\mathrm{r}=-0.448)$. Almost all of these correlations were confirmed both in men and women. Negative correlations for beer and tomato consumption were confirmed only in men. The correlations were stronger in women than in men. A weakly positive correlation between milk consumption and mortality from liver cancer $(\mathrm{r}=0.559, \mathrm{p}<0.05)$ was found only among women. The strongest correlation was found between spirits consumption and liver cancer mortality rates in women $(r=0.851, p<0.01)$. Almost all of these correlations were confirmed in both truncated ages, where correlation was not found only for tomato consumption. A negative correlation between coffee consumption and age-adjusted liver cancer mortality rates was found $(r=-0.453, p<0.05)$ only in the eldest persons. Additional analysis by gender showed a weak negative correlation between coffee intake and mortality from liver cancer in older men only $(\mathrm{r}=-0.516, \mathrm{p}<0.05)$ (data not shown). There was a lack of association for total fat consumption, read meat, pork, cheese, total drink, and apples consumption.

\section{DISCUSSION}

The analysis of time trend in liver cancer mortality in Serbia in correlation to changes in per capita food and alcohol consumption supported the unwholesome (harmful) effect of animal fat, beef, wine and spirits intake. Vegetable oil, poultry, dried meat and meat processed items, fish, eggs, yogurt, beer consumption and fruit and vegetable intake had a protective effect for liver cancer mortality rates. For women, and to a lesser extent for man, the most consistent positive correlation with liver cancer mortality rates was consumption of spirits. A weak negative correlation between coffee intake and liver cancer mortality was found only in the eldest men.

With mortality rate of 4.9 per 100,000 inhabitants in 2008, Serbia was among countries with low liver cancer mortality rate, together with Greece (5.7 per 100,000), Croatia (4.9), the Russian Federation (3.6), and the United States of America (3.6) (2). Liver cancer mortality rates in 2008 ranged from the highest, recorded in Mongolia (79.9 per 100,000), Vietnam (27.3), China (23.7) to the lowest (less than 2.0 per 100,000) recorded in the Netherlands and Norway (2). Liver cancer mortality has been on the decline over the last two decades in Serbia as well as in the Netherlands, Italy, France, and several Scandinavian countries (23). In contrast, in some developed countries (United States, European Union) an increased trend of cancer mortality in last decades has been noted $(6,7)$. In Serbia, mortality rates from liver cancer have partly resulted from implementation of a HBV vaccination programme as well as the blood products screening for $\mathrm{HCV}$ and $\mathrm{HBV}$ markers (25). However, the decreasing trend of mortality from liver cancer in the older age groups is likely to be explained by exposure to risk factors rather than the recent introduction of $\mathrm{HBV}$ vaccination in Serbia (25). The decreased mortality trend of liver cancer was probably influenced by changes in risk factors exposure, such as alcohol consumption, diet or tobacco (25).

According to the World Health Organization estimates, 30.3\% of liver cancer deaths in the world are attributable to alcohol as a risk factor (30.7\% in men and $15.7 \%$ in women) (26). The reduction in per capita alcohol consumption observed during the last decades in many European countries (except Northern European countries) has likely contributed to the decrease in cirrhosis mortality and consequent decrease in liver cancer mortality. In recent decades, in all five Scandinavian countries there has been the apparent rise in alcohol consumption, corresponding to $15 \%$ of all death cases from liver cancer in 2000 (27). From 1980-2003, in some regions of the United States of America, a correlation between elevated liver cancer mortality rates and alcohol dependence among Hispanics was demonstrated (28). The 2006 Health Survey of the Republic of Serbia revealed that $40.3 \%$ of the population drank alcohol (occasionally or daily), while the number of alcohol non-consumers increased by $5 \%$ in comparison with 2000 (25). In 2006, the average number of weekly alcoholic drinks in Serbia amounted to 6.4 - significantly less than in 2000 when the number was 8.3. According to our data, a decrease in wine and spirits consumption was correlated with reduction in liver cancer mortality. In the Japan Collaborative Cohort Study, 
Table 1. Pearson correlation coefficients between per capita food consumption and liver cancer mortality rates (age-adjusted to the World standard population per 100,000) in Serbia (excluding the Autonomous Province of Kosovo and Metohija), by age and gender, 1991-2010

\begin{tabular}{|c|c|c|c|c|c|}
\hline & Overall & Males & Females & $\begin{array}{c}\text { Truncated } \\
\text { (40-64 years) }\end{array}$ & $\begin{array}{l}\text { Truncated } \\
\text { (65+ years) }\end{array}$ \\
\hline \multicolumn{6}{|l|}{ Fat } \\
\hline Animal & $0.713^{\star *}$ & $0.633^{* *}$ & $0.742^{\star *}$ & $0.607^{\star *}$ & $0.662^{\star *}$ \\
\hline Vegetable & $-0.583^{\star *}$ & $-0.509^{*}$ & $-0.620^{\star *}$ & $-0.505^{*}$ & $-0.526^{*}$ \\
\hline Total fat & 0.298 & 0.276 & 0.295 & 0.244 & 0.298 \\
\hline \multicolumn{6}{|l|}{ Meat } \\
\hline Read meat & 0.356 & 0.349 & 0.297 & 0.363 & 0.257 \\
\hline Beef & $0.631^{* *}$ & $0.520^{*}$ & $0.689^{* *}$ & $0.643^{* *}$ & $0.457^{*}$ \\
\hline Pork & 0.033 & 0.100 & -0.085 & 0.034 & 0.023 \\
\hline Poultry & $-0.728^{* \star}$ & $-0.623^{* *}$ & $-0.790^{\star *}$ & $-0.579^{\star *}$ & $-0.695^{\star *}$ \\
\hline Dried and processed & $-0.666^{* *}$ & $-0.544^{*}$ & $-0.766^{* *}$ & $-0.543^{*}$ & $-0.625^{\star *}$ \\
\hline Fish & $-0.678^{* *}$ & $-0.581^{* *}$ & $-0.740^{* *}$ & $-0.543^{*}$ & $-0.657^{* *}$ \\
\hline Eggs & $-0.789^{* *}$ & $-0.767^{* *}$ & $-0.733^{* *}$ & $-0.681^{* *}$ & $-0.731^{* *}$ \\
\hline \multicolumn{6}{|l|}{ Milk and dairy products } \\
\hline Milk & 0.376 & 0.206 & $0.559^{*}$ & 0.296 & 0.340 \\
\hline Cheese & -0.020 & -0.065 & 0.026 & -0.011 & -0.094 \\
\hline Yogurt & $-0.710^{* *}$ & $-0.613^{* *}$ & $-0.765^{* *}$ & $-0.539^{*}$ & $-0.719^{* *}$ \\
\hline Coffee & -0.412 & -0.406 & -0.388 & -0.319 & $-0.453^{*}$ \\
\hline \multicolumn{6}{|l|}{ Alcohol beverages } \\
\hline Beer & $-0.525^{*}$ & $-0.583^{* *}$ & -0.405 & -0.395 & $-0.565^{* *}$ \\
\hline Wine & $0.632^{* *}$ & $0.591^{* *}$ & $0.608^{* *}$ & $0.664^{* *}$ & 0.424 \\
\hline Spirits & $0.745^{\star *}$ & $0.600^{* *}$ & $0.851^{* *}$ & $0.621^{\text {** }}$ & $0.669^{* *}$ \\
\hline Total & 0.065 & -0.077 & 0.228 & 0.135 & -0.074 \\
\hline \multicolumn{6}{|l|}{ Fruits and vegetables } \\
\hline Citrus fruits & $-0.690^{* *}$ & $-0.609^{* *}$ & $-0.732^{* \star}$ & $-0.521^{*}$ & $-0.696^{* *}$ \\
\hline Apple & -0.312 & -0.390 & -0.154 & -0.254 & -0.322 \\
\hline Potato & $-0.718^{\star *}$ & $-0.779^{* \star}$ & $-0.556^{\star}$ & $-0.756^{\star *}$ & $-0.558^{\star}$ \\
\hline Cabbage & $-0.703^{* *}$ & $-0.743^{\star *}$ & $-0.573^{* *}$ & $-0.687^{\star *}$ & $-0.581^{* *}$ \\
\hline Pepper & $-0.572^{\star *}$ & $-0.510^{*}$ & $-0.591^{* *}$ & -0.422 & $-0.581^{* *}$ \\
\hline Tomato & $-0.448^{*}$ & $-0.475^{*}$ & -0.355 & -0.347 & -0.442 \\
\hline
\end{tabular}

positive associations were found between fat intake and liver cancer mortality, but there were no consistent associations with beef, processed meat or chicken consumption (29). An inverse association observed between liver cancer and white meat (fish or poultry) intake (20) was confirmed in our study. An inverse correlation between the liver cancer mortality and vegetable and fruit consumption was observed in Serbia as well as in many reports $(18,19)$. This probable effect has been related to specific micronutrients contained in vegetables and fruit. Potentially protective factors include various carotenoids, folic acid, vitamin C, flavonoids, phytoestrogens, and fiber. An inverse association of coffee consumption with liver cancer, found in many epidemiological studies $(17,30)$, was observed among the eldest men in Serbia only. Coffee intake was inversely associated with incident liver cancer and mortality from chronic liver disease, irrespective of presence of diabetes, HBV and HCV infections (17). Coffee is rich in antioxidants and other components, which could explain potentially anticarcinogenic effect of the coffee consumption (31). However, the possible beneficial effect of higher coffee consumption on liver cancer mortality could be an indirect link, i.e. perhaps it is a consequence of association between higher consumption of coffee with lower consumption of spirits. This link has been recognized in our study (non significant negative correlation between coffee and spirits intake was observed: $r=-0.432, p>0.05$ ) and some other studies as well $(16,32)$.

Milk intake was associated with higher mortality from liver cancer for men and women in the Japan Collaborative Cohort Study (29). In Serbia, milk consumption correlated with mortality from liver cancer among women. A role of diet in liver carcinogenesis is plausible since most substances or metabolites, including carcinogens, are excreted via the bile. Also, women are possibly more susceptible to liver toxins (e.g. hormonal factors or the presence of larger fat depots in women could be resulting in greater accumulation of some lipophilic toxic contaminants, 
such as organic solvents, organochlorines, additives, pesticides, etc.) (33). High consumption of milk may reflect an overall high dietary fat intake (particularly saturated fatty acids) or milk may contain growth factors (such as insulin-like growth factor I) or large amounts of estrogens and progesterone associated with cancer risk (34). Nonetheless, an inverse association between milk and dairy products and liver cancer risk was observed in other studies in Italy and Greece $(35,36)$.

\section{Strengths and Limitations of the Study}

Ecological studies may be useful in identifying cancer risk factors thanks to comparison of different populations or within the same population between different periods. The main advantage of ecological studies is that they can be done quickly and inexpensively. Advantages of mortality statistics data in Serbia are national coverage and consistent quality. According to the percentage of new malignant tumour cases registered by a death report as well as the percentage of histologically and cytologically-verified malignant tumours of the total number of reported cancer cases in the Registry, the World Health Organization assessed data quality and confirmed that Serbia has comprehensive death registration systems (37). The proportion of cases with uncertain death cause (revision 9 codes 780-799 and revision 10 codes R00-R99) in the observed period was on an average $6.8 \%$, with a non-significant decreasing trend $(p=0.137)$, so that significant changes in mortality from liver cancer could not be attributed only to the improvement of quality of mortality statistics in Serbia $(24,38)$.

Nevertheless, ecological studies are not capable of linking the liver cancer experience of any individual with their diet, since the only information available is the country for which cancer mortality rate and average per capita food consumption were estimated. Of course, there always is a question of the quality of data collected. Mortality data for liver cancer are extremely difficult to interpret, due to the large number of secondary tumours, which are difficult to separate from primary liver cancers without histological verification. Inaccuracies in the death certification practices can occur for several reasons, such as errors in the selection of the main cause of death, precision of the medical diagnosis, coding of the cause of death, etc. The registration of autopsies in Serbia began in 2006, so that we have no data on the impact of changes in the rate of autopsies on the coding of causes of death in the observed period. Further, one limitation of the present study is that we were not determined to study whether the several co-morbidities (e.g. cirrhosis, etc.) or unhealthy life style (tobacco use, obesity, etc.) influenced both food consumption and liver cancer mortality.

In conclusion, correlations between liver cancer and dietary habits were observed and further effort is needed in order to investigate a possible causative association using epidemiological analytical studies.

\section{Acknowledgement}

This work was supported by the Ministry of Education and Science of the Republic of Serbia, through the Contract No. 175042.

\section{Conflict of Interests}

None declared

\section{Declaration of Authorship}

MI performed study concept and design, data collection, data analysis, interpretation of the results, manuscript preparation, manuscript editing, and manuscript review; KR performed data analysis, manuscript editing and manuscript review; SK performed data analysis, manuscript editing and manuscript review; II performed data collection, data analysis, interpretation of the results, manuscript preparation, manuscript editing, and manuscript review.

\section{Ethical Approval}

This study is a part of larger research approved by the Ethics Committee of the Faculty of Medical Sciences, University of Kragujevac (Ref. No.: 01-4806), entitled "The survival of patients suffering from the most common chronic diseases (malignant tumors, cardiovascular and cerebrovascular diseases)".

\section{REFERENCES}

1. Jemal A, Bray F, Center MM, Ferlay J, Ward E, Forman D. Global cancer statistics. CA Cancer J Clin. 2011 Mar-Apr;61(2):69-90.

2. Ferlay J, Shin HR, Bray F, Forman D, Mathers C, Parkin DM. GLOBOCAN 2008, Cancer Incidence and Mortality Worldwide. Lyon: International Agency for Research on Cancer; 2010.

3. Ferlay J, Shin HR, Bray F, Forman D, Mathers C, Parkin DM. Estimates of worldwide burden of cancer in 2008: GLOBOCAN 2008. Int J Cancer. 2010 Dec 15;127(12):2893-917.

4. Jemal A, Siegel R, Ward E, Hao Y, Xu J, Murray T, et al. Cancer statistics, 2008. CA Cancer J Clin. 2008 Mar-Apr;58(2):71-96.

5. Bosch FX, Ribes J, Díaz M, Cléries R. Primary liver cancer: worldwide incidence and trends. Gastroenterology. 2004 Nov;127(5 Suppl 1):S5-16.

6. Bosetti C, Bertuccio P, Levi F, Lucchini F, Negri E, La Vecchia C. Cancer mortality in the European Union, 1970-2003, with a joinpoint analysis. Ann Oncol. 2008 Apr;19(4):631-40.

7. Howlader N, Noone AM, Krapcho M, Garshell J, Neyman N, Altekruse SF, et al., editors. SEER Cancer Statistics Review, 1975-2010. Bethesda: National Cancer Institute; 2013.

8. Guo P, Huang ZL, Yu P, Li K. Trends in cancer mortality in China: an update. Ann Oncol. 2012 Oct;23(10):2755-62.

9. Katanoda K, Matsuda T, Matsuda A, Shibata A, Nishino Y, Fujita M, et al. An updated report of the trends in cancer incidence and mortality in Japan. Jpn J Clin Oncol. 2013 May;43(5):492-507.

10. Williams G, Mans DR, Garssen J, Visser O, Kramer D, Kunst AE. Cancer incidence and mortality of Surinamese migrants in the Netherlands: in-between Surinamese and Dutch levels? Cancer Causes Control. 2013 Jul;24(7):1375-83.

11. Perz JF, Armstrong GL, Farrington LA, Hutin YJ, Bell BP. The contributions of hepatitis $B$ virus and hepatitis $C$ virus infections to cirrhosis and primary liver cancer worldwide. J Hepatol. 2006 Oct;45(4):529-38.

12. de Martel C, Ferlay J, Franceschi S, Vignat J, Bray F, Forman D, et al. Global burden of cancers attributable to infections in 2008: a review and synthetic analysis. Lancet Oncol. 2012 Jun;13(6):607-15.

13. Parkin DM, Boyd L, Walker LC. 16. The fraction of cancer attributable to lifestyle and environmental factors in the UK in 2010. Br J Cancer. 2011 Dec 6;105 Suppl 2:S77-81.

14. Liu Y, Wu F. Global burden of aflatoxin-induced hepatocellular carcinoma: a risk assessment. Environ Health Perspect. 2010 Jun;118(6):81824.

15. El-Serag HB. Epidemiology of hepatocellular carcinoma in USA. Hepatol Res. 2007 Sep;37 Suppl 2:S88-94.

16. Bravi F, Bosetti C, Tavani A, Bagnardi V, Gallus S, Negri E, et al. Coffee drinking and hepatocellular carcinoma risk: a meta-analysis. Hepatology. 2007 Aug;46(2):430-5

17. Inoue M, Kurahashi N, Iwasaki M, Shimazu T, Tanaka Y, Mizokami M, et al.; Japan Public Health Center-Based Prospective Study Group. Effect of coffee and green tea consumption on the risk of liver cancer: cohort analysis by hepatitis virus infection status. Cancer Epidemiol Biomarkers Prev. 2009 Jun;18(6):1746-53. 
18. Sauvaget C, Nagano J, Hayashi M, Spencer E, Shimizu Y, Allen N. Vegetables and fruit intake and cancer mortality in the Hiroshima/Nagasaki Life Span Study. Br J Cancer. 2003 Mar 10;88(5):689-94.

19. Fedirko V, Trichopolou A, Bamia C, Duarte-Salles T, Trepo E, Aleksandrova $\mathrm{K}$, et al. Consumption of fish and meats and risk of hepatocellular carcinoma: the European Prospective Investigation into Cancer and Nutrition (EPIC). Ann Oncol. 2013 Aug;24(8):2166-73.

20. Daniel CR, Cross AJ, Graubard BI, Hollenbeck AR, Park Y, Sinha R. Prospective investigation of poultry and fish intake in relation to cancer risk. Cancer Prev Res (Phila). 2011 Nov;4(11):1903-11.

21. Zhang W, Xiang YB, Li HL, Yang G, Cai H, Ji BT, et al. Vegetable-based dietary pattern and liver cancer risk: results from the Shanghai women's and men's health studies. Cancer Sci. 2013 Oct;104(10):1353-61.

22. Bosetti C, Filomeno M, Riso P, Polesel J, Levi F, Talamini R, et al. Cruciferous vegetables and cancer risk in a network of case-control studies. Ann Oncol. 2012 Aug;23(8):2198-203.

23. Bosetti C, Levi F, Boffetta P, Lucchini F, Negri E, La Vecchia C. Trends in mortality from hepatocellular carcinoma in Europe, 1980-2004. Hepatology. 2008 Jul;48(1):137-45.

24. Statistical Office of the Republic of Serbia. Demographic Yearbook in the Republic of Serbia, 1991-2010. Belgrade (Serbia): Statistical Office of the Republic of Serbia; 2011.

25. Ministry of Health, Republic of Serbia. National Health Survey, Serbia 2006: key findings. Belgrade: Ministry of Health, Republic of Serbia; 2007.

26. World Health Organization. Global status report on alcohol and health Geneva: WHO; 2011

27. Møller B, Fekjaer H, Hakulinen T, Tryggvadóttir L, Storm HH, Talbäck $\mathrm{M}$, et al. Prediction of cancer incidence in the Nordic countries up to the year 2020. Eur J Cancer Prev. 2002 Jun;11 Suppl 1:S1-96.

28. Wang NK-L. A geographic analysis of liver cancer mortality and alcohol dependence or abuse in Texas and the U.S., 1980-2003 [dissertation]. Houston: University of Texas School of Public Health; 2008.

29. Iso H, Kubota Y; Japan Collaborative Cohort Study for Evaluation of Cancer. Nutrition and disease in the Japan Collaborative Cohort Study for Evaluation of Cancer (JACC). Asian Pac J Cancer Prev. 2007;8 Suppl:35-80
30. Montella M, Polesel J, La Vecchia C, Dal Maso L, Crispo A, Crovatto M, et al. Coffee and tea consumption and risk of hepatocellular carcinoma in Italy. Int J Cancer. 2007 Apr 1;120(7):1555-9.

31. Ruhl CE, Everhart JE. Coffee and caffeine consumption reduce the risk of elevated serum alanine aminotransferase activity in the United States. Gastroenterology. 2005 Jan;128(1):24-32.

32. Inoue M, Yoshimi I, Sobue T, Tsugane S; JPHC Study Group. Influence of coffee drinking on subsequent risk of hepatocellular carcinoma: a prospective study in Japan. J Natl Cancer Inst. 2005 Feb 16;97(4):293300

33. Davoodi H, Esmaeili S, Mortazavian AM. Effects of milk and milk products consumption on cancer: a review. Compr Rev Food Sci Foos Saf. 2013;12(3):249-64

34. Wu AH, Pike MC, Stram DO. Meta-analysis: dietary fat intake, serum estrogen levels, and the risk of breast cancer. J Natl Cancer Inst. 1999 Mar 17;91(6):529-34.

35. Talamini R, Polesel J, Montella M, Dal Maso L, Crispo A, Tommasi LG, et al. Food groups and risk of hepatocellular carcinoma: A multicenter case-control study in Italy. Int J Cancer. 2006 Dec 15;119(12):2916-21.

36. Kuper H, Tzonou A, Lagiou P, Mucci LA, Trichopoulos D, Stuver SO, et al. Diet and hepatocellular carcinoma: a case-control study in Greece. Nutr Cancer. 2000;38(1):6-12.

37. Mathers CD, Fat DM, Inoue M, Rao C, Lopez AD. Counting the dead and what they died from: an assessment of the global status of cause of death data. Bull World Health Organ. 2005 Mar;83(3):171-7.

38. Institute of Public Health of Serbia "Dr. Milan Jovanovic Batut". National Cancer Screening Office. Cancer incidence and mortality in Central Serbia [Internet]. Belgrade: Institute of Public Health of Serbia "Dr. Milan Jovanovic Batut" [cited 2015 Sep 3]. Available from: http://www. skriningsrbija.rs/eng/publications/cancer-incidence-and-mortality-incentral-serbia/.

Received November 9, 2014 Accepted in revised form September 3, 2015 